\title{
Cation $-\pi$ interactions in competition with cation microhydration: a theoretical study of alkali metal cation-pyrene complexes
}

\author{
Hasan Pašalić $^{1} \cdot$ Adelia J. A. Aquino $^{2,3}$ • Daniel Tunega ${ }^{3}$ (D) - Georg Haberhauer $^{3}$. \\ Martin H. Gerzabek ${ }^{3}$ - Hans Lischka ${ }^{1,2}$
}

Received: 29 December 2016 / Accepted: 27 February 2017 / Published online: 23 March 2017

(C) The Author(s) 2017. This article is published with open access at Springerlink.com

\begin{abstract}
Cation $-\pi$ interactions were systematically investigated for the adsorption of $\mathrm{H}^{+}$and alkali metal cations $\mathrm{M}^{+}$to pyrene by means of Møller-Plesset perturbation theory (MP2) and density functional theory (DFT). The main aims were to determine the preferred adsorption sites and how the microhydration shell influences the adsorption process. The preferred adsorption sites were characterized in terms of structural parameters and energetic stability. Stability analysis of the $\mathrm{M}^{+}$-pyrene complexes revealed that the binding strength and the barrier to transitions between neighboring sites generally decreased with increasing cation size from $\mathrm{Li}^{+}$to $\mathrm{Cs}^{+}$. Such transitions were practically barrierless $(\ll<1 \mathrm{kcal} / \mathrm{mol})$ for the large $\mathrm{Rb}^{+}$and $\mathrm{Cs}^{+}$ions. Further, the influence of the first hydration shell on the adsorption behavior was investigated for $\mathrm{Li}^{+}$and $\mathrm{K}^{+}$as representatives of small and large (alkali metal) cations, respectively. While the isolated complexes possessed only one minimum, two minima-corresponding to an inner and an outer complex-were observed for microhydrated complexes. The small $\mathrm{Li}^{+}$ion formed a stable hydration shell and preferentially interacted with water
\end{abstract}

Georg Haberhauer is deceased.

Daniel Tunega

daniel.tunega@boku.ac.at

Hans Lischka

hans.lischka@univie.ac.at

1 Institute for Theoretical Chemistry, University of Vienna, Währinger Strasse 17, 1090 Vienna, Austria

2 School of Pharmaceutical Sciences and Technology, Tianjin University, 92 Weijin Road, Nankai District, Tianjin 300072, People's Republic of China

3 Institute for Soil Research, University of Natural Resources and Life Sciences Vienna, Peter-Jordan-Strasse 82, 1190 Vienna, Austria rather than pyrene. In contrast, $\mathrm{K}^{+}$favored cation $-\pi$ over cation-water interactions. It was found that the mechanism for complex formation depends on the balance between cation $-\pi$ interactions, cation-water complexation, and the hydrogen bonding of water to the $\pi$-system.

Keywords Cation $-\pi$ interactions $\cdot$ Microhydration $\cdot$ Alkali metal cation-pyrene $\cdot$ DFT

\section{Introduction}

Cation- $\pi$ interactions are among the strongest noncovalent interactions; in many cases they are stronger than hydrogen bonds and van der Waals interactions [1,2]. They are frequently encountered in nature and play pivotal roles in complex biological systems such as cation complexes with proteins, chemical catalysis, and solid-state physics [1, 3, 4]. Another interesting area where cation $-\pi$ interactions play a significant role is soil chemistry. Cation $-\pi$ interactions occur in several adsorption processes where metal cations interact with aromatic moieties in soil organic matter and black carbon [2]. These interactions have been considered to be more important than $\pi-\pi$ stacking and hydrophobic interactions [2]. The nature of cation $-\pi$ interactions is not purely electrostatic. A symmetry-adapted perturbation theory (SAPT) study by Singh et al. [5] demonstrated that, besides the electrostatic component, interactions due to induction and dispersion make an important contribution. Cation $-\pi$ interactions have been studied theoretically for various $\pi$-systems, predominantly with mono- and divalent cations, using a wide variety of methods ranging from density functional theory to highlevel ab initio methods. Typical cations studied in this context are the alkali and alkali earth metal cations, while benzene is the typical representative of $\pi$-systems [6-24]. Theoretical 
studies have also investigated transition metal cations such as $\mathrm{Zn}^{2+}$ and $\mathrm{Cd}^{2+}[25]$. Several experimental investigations performed in the gas phase using mass spectrometric methods have been carried out to study cation $-\pi$ interactions, with benzene employed as the aromatic system $[1,2,26]$. For example, Sunner et al. [27] reported in 1981 that the $\mathrm{K}^{+}$-benzene interaction is stronger than the $\mathrm{K}^{+}$-water interaction. About 20 years later, Cabarcos et al. $[28,29]$ found that $\mathrm{K}^{+}$favors cation $-\pi$ (benzene) over cation-water interactions using infrared spectroscopic and mass spectrometric methods. In stark contrast, $\mathrm{Na}^{+}$was found to prefer the aqueous environment. These findings were crucial to advancing our understanding of selective ionic channels, as hydrated $\mathrm{Na}^{+}$is too large to pass through a pore. In addition to theoretical studies of small molecules such as benzene, attention has also been directed towards larger aromatic systems. For example, Burk et al. [30] studied the interactions of $\mathrm{Cs}^{+}$with a set of neutral and anionic compounds related to soil organic matter (e.g., unsubstituted and substituted aromatic compounds such as phenolic acids and phenolates) theoretically. The authors found that this cation had greater affinity for the substituted aromatic compounds than the unsubstituted ones. Gal et al. [31] investigated the adsorption of $\mathrm{Li}^{+}$to large polycyclic aromatic hydrocarbons (PAH) up to circumcoronene. They showed that the interaction energy decreases with increasing number of fused rings. Similar trends were reported for the transition state barriers in that work. Various linear and branched PAHs were chosen to represent graphene nanoflakes, and their interactions with $\mathrm{Li}^{+}$and $\mathrm{Mg}^{2+}$ ions were studied theoretically, which highlighted an effect of ring size on the stability of the cation $-\pi$ complexes [12]. Studies of cation $-\pi$ interactions of alkali and alkaline earth cations with graphene models using density functional theory (DFT) with the M06-2X functional [32] showed that the binding strength depends significantly on the cation studied [33]. The geometries, electronic structures, and magnetic properties of alkali earth metal atoms absorbed onto graphene have also been investigated by DFT calculations using periodic boundary conditions [34].

As previously noted, cation $-\pi$ and cation-water interactions generally compete. Thus, it is important to consider solvent effects, especially explicit solvent water molecules, in simulations. In a combined experimental/computational study, Meng et al. [35] investigated the adsorption of $\mathrm{Na}^{+}$and $\mathrm{K}^{+}$to a graphite surface, including hydration effects. Their results were in general agreement with those obtained by Cabarcos et al. [29] in a previous experimental work on $\mathrm{Na}^{+}$-benzene and $\mathrm{K}^{+}$-benzene complexes.

In the work reported in the present paper, in order to improve our knowledge of the characteristics of the adsorption of alkali cations to larger PAHs, the processes associated with the adsorption of a whole series of alkali metal cations $\left(\mathrm{Li}^{+}\right.$to $\mathrm{Cs}^{+}$) to pyrene were studied systematically. In contrast to benzene, pyrene is large enough to represent $\pi$-systems that possess several potential adsorption sites, but is also sufficiently small to allow us to perform extensive quantum chemical calculations on it. It can be further used as a prototype model for nanographene flakes or, more generally, as an initial model for the surface of black carbon, since graphitic layers are a major component of natural black carbon [36]. Pyrene and pyrene-carbon vacancy defect structures have also been successfully used to study the chemisorption of a hydrogen atom onto graphene nanoflakes [37]. The present study of the interactions of alkali cations was completed by exploring the bonding of $\mathrm{H}^{+}$to pyrene. This work particularly focused on attempting to understand microhydration effects and the aforementioned competition between hydration and cation $-\pi$ interactions. Thus, the role of the first hydration shell in adsorption structures is discussed here in detail, paying special attention to hydrogen bonding and the balance between hydration and direct adsorption.

\section{Computational methods}

Cation- $\pi$ interactions were investigated for $\mathrm{M}^{+}-$pyrene complexes $(\mathrm{M}=\mathrm{H}, \mathrm{Li}, \mathrm{Na}, \mathrm{K}, \mathrm{Rb}$, and $\mathrm{Cs})$ by means of secondorder Møller-Plesset perturbation (MP2) theory [38, 39] and density functional theory (DFT) using the exchangecorrelation functional PBE [40, 41]. For both methods, the resolution of the identity (RI) approximation [42, 43] and a flexible def2-TZVPP basis set were applied [44]. The computationally efficient RI approximation has been demonstrated to give almost identical results for interaction energies and equilibrium distances of cation $-\pi$ complexes to those afforded by pure MP2 and DFT methods [45]. The def2-TZVPP basis set with relativistic effective core potentials (ECP) was used for rubidium and cesium [46, 47]. For all of the complexes studied, full geometry optimizations were performed in the gas phase at the MP2 and PBE levels. Transition states connecting the located energy minima for the $\mathrm{M}^{+}$-pyrene complexes were optimized by means of PBE. The nature of each structure obtained was characterized by a vibrational mode analysis. Harmonic vibrational frequencies and thermodynamic properties were calculated within the standard harmonic oscillatorrigid rotator-ideal gas approximation for $T=298 \mathrm{~K}$ and $p=$ $1 \mathrm{~atm}$. The final gas-phase interaction energies of the $\mathrm{M}^{+}-$ pyrene complexes were corrected for basis set superposition error (BSSE) using the counterpoise method as proposed by Boys and Bernardi [48]. Potential energy curves for the approach of isolated and hydrated $\mathrm{Li}^{+}$and $\mathrm{K}^{+}$ions to the pyrene surface were calculated at the PBE level, considering the first hydration shell. $\mathrm{Li}^{+}$and $\mathrm{K}^{+}$were selected as representatives of small and large alkali metal cations, respectively, with the first hydration shells comprising four $\left(\mathrm{Li}^{+}\right)$and eight $\left(\mathrm{K}^{+}\right)$water molecules, respectively. Throughout those calculations, the water molecules were fully optimized for each fixed $\mathrm{M}^{+} \ldots$ 
pyrene distance. All calculations were performed using the Turbomole program [49].

\section{Results and discussion}

\section{$\mathrm{H}^{+}$-pyrene}

The stability of protonated pyrene with respect to protonation sites I-V (Fig. 1; sites I-V are peripheral carbon atoms of pyrene as well as an internal carbon) was studied by means of MP2 and PBE calculations. The interaction (formation) energies $\Delta E_{\mathrm{f}}$, the enthalpies $\Delta H_{\mathrm{f}}$, the Gibbs free energies $\Delta G_{\mathrm{f}}$, and the relative energetic stabilities $\Delta \Delta E_{\mathrm{r}}$ are collected in Table 1 for both methods. The following order of stability is observed in the results from both MP2 and PBE: III $<$ I $<$ IV $<$ $\mathrm{V}<\mathrm{II}$. Protonation of the outer carbon atoms, leading to the formation of $\mathrm{C}-\mathrm{H}$ bonds, is preferred (III, I, and IV). During the protonation of these sites, $\mathrm{H}^{+}$is bound covalently to the carbon atom, resulting in a $\mathrm{CH}_{2}$ group, and a positive charge is generated on the neighboring carbon atom. The resulting $\mathrm{C}-\mathrm{H}$ bond in the $\mathrm{H}^{+}$-benzene system has previously been shown to be covalent [50], and is in good agreement with our result. Site III (the $\alpha$ or $\mathrm{C} 1$ carbon of pyrene) is the most stable of the three peripheral carbon atoms, with calculated relative MP2 energy differences $\left(\Delta \Delta E_{\mathrm{r}}\right)$ with respect to sites I and IV of 10.73 and $15.77 \mathrm{kcal} / \mathrm{mol}$, respectively. This is in good agreement with results obtained in earlier computational investigations, which afforded values of 9.9 and $15.7 \mathrm{kcal} / \mathrm{mol}(\mathrm{HF} / 6$ $31 \mathrm{G}$ ) [51] and 10.5 and $15.0 \mathrm{kcal} / \mathrm{mol}$ (B3LYP/6-31G) using significantly smaller basis sets [52]. Preferential proton attack on the $\alpha$-carbon was also observed in an NMR study by Laali [53] and was qualitatively explained by the larger number of resonance structures in this case compared to the other protonated pyrene structures [51].

The protonation of pyrene at carbon atoms that are not already bonded to $\mathrm{H}$ atoms is energetically considerably less

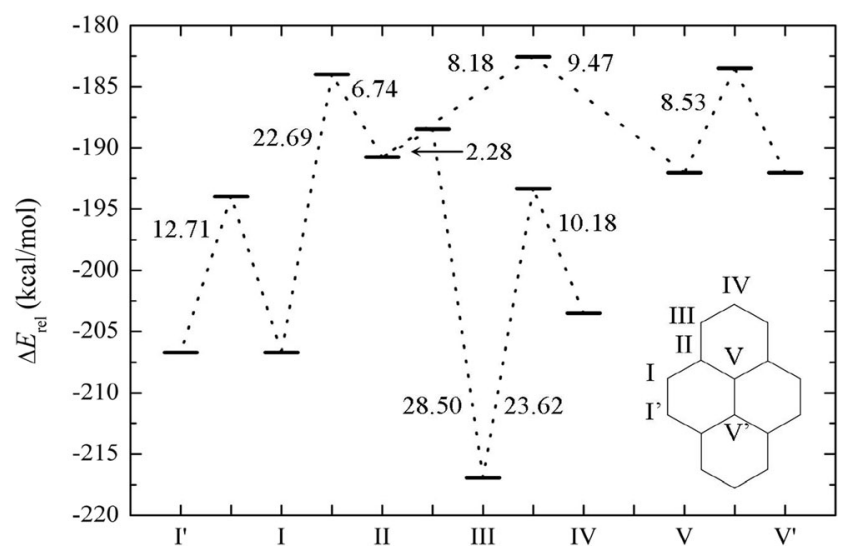

Fig. 1 Energy profile and transition barriers (kcal/mol) for $\mathrm{H}^{+}$-pyrene, calculated using the PBE/def2-TZVPP method. Sites I and I' are equivalent due to symmetry, as are $\mathrm{V}$ and $\mathrm{V}^{\prime}$ favorable. Similar MP2 interaction energies (differing by only $0.1 \mathrm{kcal} / \mathrm{mol}$; Table 1) are computed for site V (a central carbon atom; see Fig. 1) and site II. The relative energy difference from the most stable structure (III) amounts to about $27 \mathrm{kcal} /$ mol. The order of stability found for the interaction energies is preserved for the enthalpies and Gibbs free energies (Table 1).

The interaction energies calculated at the PBE level are stronger by about $10 \mathrm{kcal} / \mathrm{mol}$ than those obtained using MP2, whereas the relative energies $\Delta \Delta E_{\mathrm{r}}$ yielded by the two methods are in good agreement (differing by $<2.5 \mathrm{kcal} /$ mol; Table 1). Since PBE reproduces the order of stability and the relative energy differences afforded by MP2, it was further used to calculate the transition barriers. The energy barriers $(\mathrm{kcal} / \mathrm{mol})$ to transitions between neighboring protonation sites are presented in Fig. 1. As can be seen, only the transition from the least favorable structure (II) to the most stable one (III) has a relatively small energy barrier $(2.3 \mathrm{kcal} / \mathrm{mol})$. All the other barriers are close to or greater than $10 \mathrm{kcal} / \mathrm{mol}$.

\section{Alkali metal cation-pyrene}

The stabilities of the alkali metal cation-pyrene complexes were investigated by means of MP2 and PBE calculations. To localize the energy minima and transition states of the alkali metal cation-pyrene complexes, the pyrene surface was initially scanned by moving the $\mathrm{Li}^{+}$cation over the pyrene plane at a fixed distance of $1.8 \AA$ from it using the PBE functional and the SVP basis set. The pyrene geometry was kept fixed. From the resulting energy contour plot (Fig. 2), two potential energy minima (M1 and M2) and two potential transition states (TS1 and TS2) were localized (Fig. 3). In the subsequent calculations, alkali cations were placed at the M1/

Table 1 Formation energies $\Delta E_{\mathrm{f}}$, energetic stabilities $\Delta \Delta E_{\mathrm{r}}$ with respect to site III, enthalpies $\Delta H_{\mathrm{f}}$, and Gibbs free energies $\Delta G_{\mathrm{f}}$ at $T=$ $298 \mathrm{~K}$ for energy minima I-V (see Fig. 1) of the $\mathrm{H}^{+}$-pyrene system calculated at the RI-MP2 and RI-PBE levels using the def2-TZVPP basis set. All values are given in $\mathrm{kcal} / \mathrm{mol}$

\begin{tabular}{lllll}
\hline $\mathrm{H}^{+}$ & $\Delta E_{\mathrm{f}}$ & $\Delta \Delta E_{\mathrm{r}}$ & $\Delta H_{\mathrm{f}}$ & $\Delta G_{\mathrm{f}}$ \\
\hline RI-MP2 & & & & \\
I & -196.83 & 10.73 & -191.22 & -184.90 \\
II & -180.64 & 26.92 & -175.74 & -169.37 \\
III & -207.56 & 0.00 & -201.61 & -195.25 \\
IV & -191.79 & 15.77 & -186.35 & -179.98 \\
V & -180.71 & 26.85 & -175.89 & -169.44 \\
RI-PBE & & & & \\
I & -206.69 & 10.27 & -201.16 & -195.01 \\
II & -190.74 & 26.22 & -185.86 & -179.46 \\
III & -216.96 & 0.00 & -211.05 & -204.78 \\
IV & -203.51 & 13.45 & -198.29 & -192.06 \\
V & -192.03 & 24.93 & -186.98 & -180.49 \\
\hline
\end{tabular}




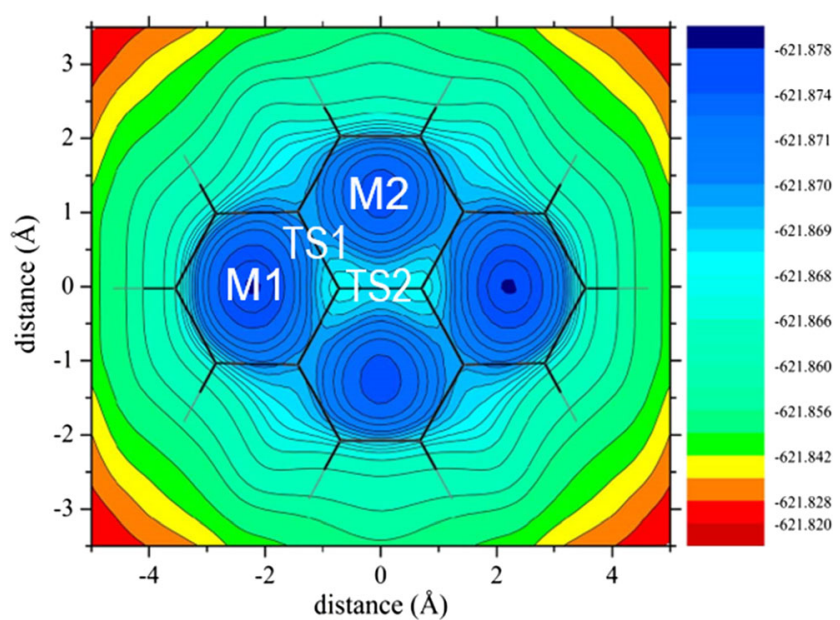

Fig. 2 PBE/SVP-calculated energy contour map for the $\mathrm{Li}^{+}-$pyrene complex with a $\mathrm{Li}^{+} \cdots$ pyrene distance of $1.8 \AA$. Potential energy minima and transition states are indicated in the figure

M2 sites and their final positions were then optimized. Similarly, for the transition states, the cations were placed in the TS1/TS2 positions and their positions perpendicular to the pyrene plane were optimized.

M1 corresponds to the structure where the alkali metal cation is located above the outer pyrene ring (Fig. 3). In the case of M2, the alkali metal cation is located above the inner pyrene ring. The MP2- and PBE-calculated interaction (formation) energies $\left(\Delta E_{\mathrm{f}}\right)$, enthalpies $\left(\Delta H_{\mathrm{f}}\right)$, and Gibbs free energies $\left(\Delta G_{\mathrm{f}}\right)$ for both energy minima are collected in Table 2.

Inspection of the MP2 results (Table 2) indicates that the interaction energy decreases with increasing alkali metal cation size except that it is less for $\mathrm{Rb}^{+}$than for $\mathrm{Cs}^{+}$(although the difference between those two values is a few tenths of a $\mathrm{kcal} / \mathrm{mol})$. It is also apparent that the MP2-calculated $\Delta E_{\mathrm{f}}$ values for the larger cations $\mathrm{K}^{+}, \mathrm{Rb}^{+}$, and $\mathrm{Cs}^{+}$lie within $1 \mathrm{kcal} / \mathrm{mol}$ of each other. The order of stability is the same for both M1 and M2 (Table 2). For $\mathrm{Li}^{+}$, the outer pyrene ring (M1, Fig. 3) is the preferred adsorption site; the difference in energy from the $\mathrm{M} 2$ site amounts to about $\sim 1.4 \mathrm{kcal} / \mathrm{mol}$. This difference decreases to $\sim 0.4 \mathrm{kcal} / \mathrm{mol}$ for $\mathrm{Na}^{+}$. For the larger cations it is almost negligible, indicating that adsorption to the different pyrene rings is equally probable for the larger alkali metal cations (Table 2). The preference of the smaller cations
$\mathrm{Li}^{+}$and $\mathrm{Na}^{+}$for the $\mathrm{M} 1$ adsorption site can be explained by the molecular electrostatic potential of pyrene, which is more attractive above the outer (M1) than the inner (M2) ring, respectively [31]. When the interaction energies $\left(\Delta E_{\mathrm{f}}\right.$, Table 2$)$ are calculated at the PBE level, the trend observed for the MP2 results is basically preserved. The PBE binding energies also decrease steadily with increasing cation size. This trend was also reported for the stability of $\mathrm{M}^{+}$-benzene complexes $[1,6$, $8,26]$. The outlined stability trends of $\Delta E_{\mathrm{f}}$ are also preserved for the enthalpies $\left(\Delta H_{\mathrm{f}}\right)$ and Gibbs free energies $\left(\Delta G_{\mathrm{f}}\right.$, Table 2). Although a strong destabilizing entropic $(T \Delta S)$ contribution is also observed $(\sim 6-7 \mathrm{kcal} / \mathrm{mol})$, all of the complexes are stable according to their $\Delta G_{\mathrm{f}}$ values at both the MP2 and PBE levels (Table 2).

As also done for the $\mathrm{H}^{+}$-pyrene complexes, transition states (TS1, TS2) connecting the energy minima (M1 and M2, Fig. 3) and the corresponding transition energy barriers were calculated for the alkali metal cation-pyrene complexes. The energy profiles and barrier heights $(\mathrm{kcal} / \mathrm{mol})$ calculated at the PBE level are presented in Fig. 4. In parallel with a decrease in the difference between the stabilities of the two minima M1 and M2 with increasing cation size, a decrease in transition barrier height is also observed. The smaller alkali metal cations $\mathrm{Li}^{+}$and $\mathrm{Na}^{+}$both have non-negligible transition barriers. For the $\mathrm{Li}^{+}$complex, the transition barrier from $\mathrm{M} 1$ to $\mathrm{M} 2$ amounts to $7.4 \mathrm{kcal} / \mathrm{mol}$. In the opposite direction (M2 to M1), the barrier drops to $5.3 \mathrm{kcal} / \mathrm{mol}$. Both values agree well with those previously calculated at the B3LYP/6311+ G(3df,2p) level: 6.8 and $4.5 \mathrm{kcal} / \mathrm{mol}$, respectively [31]. The barrier to the transition between the inner rings (M2 to M2), $6.2 \mathrm{kcal} / \mathrm{mol}$ (Fig. 3), is between the values for the forward (M1 to M2) and backward (M2 to M1) transitions.

The $\mathrm{K}^{+}$-pyrene complex represents an intermediate case between the smaller and bigger cations. Its barrier is around $1 \mathrm{kcal} / \mathrm{mol}$ for the transition from M1 to M2 (TS1), and it is even lower for the M2 to M2 transition (TS2) (Fig. 4). Since the transition barrier heights for the big alkali metal cations $\mathrm{Rb}^{+}$and $\mathrm{Cs}^{+}$are expected to be even lower, the respective transition states were not calculated explicitly. Thus, for $\mathrm{Rb}^{+}$ and $\mathrm{Cs}^{+}$, all possible transitions are expected to be virtually barrierless, indicating that these large alkali metal cations are highly mobile on pyrene (and generally on any large $\pi$ -
Fig. 3 Minimum-energy sites (M1 and M2) and transition states (TS1 and TS2) for alkali metal cation-pyrene complexes

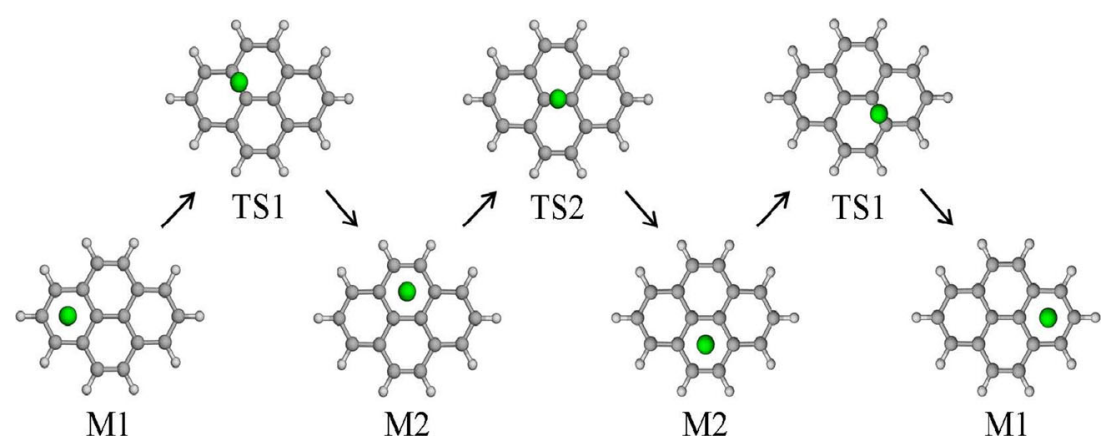


Table 2 BSSE-corrected formation energies $\Delta E_{\mathrm{f}}$, enthalpies $\Delta H_{\mathrm{f}}$, and Gibbs free energies $\Delta G_{\mathrm{f}}$ at $T=298 \mathrm{~K}$ for the energy minima (M1, M2) of alkali metal cation-pyrene complexes, as calculated at the RI-MP2 and RI-PBE levels using the def2-TZVPP basis set. All values are given in $\mathrm{kcal} / \mathrm{mol}$

\begin{tabular}{lllllll}
\hline & $\Delta E_{\mathrm{f}}$ & $\Delta H_{\mathrm{f}}$ & $\Delta G_{\mathrm{f}}$ & $\Delta E_{\mathrm{f}}$ & $\Delta H_{\mathrm{f}}$ & $\Delta G_{\mathrm{f}}$ \\
\hline $\mathrm{M} 1$ & $\mathrm{RI}-\mathrm{MP} 2$ & & & $\mathrm{RI}-\mathrm{PBE}$ & & \\
$\mathrm{Li}^{+}$ & -41.90 & -40.97 & -33.83 & -45.49 & -44.52 & -37.34 \\
$\mathrm{Na}^{+}$ & -27.11 & -26.45 & -19.90 & -29.11 & -28.89 & -22.71 \\
$\mathrm{~K}^{+}$ & -21.63 & -21.01 & -14.66 & -20.36 & -20.13 & -14.52 \\
$\mathrm{Rb}^{+}$ & -20.84 & -20.16 & -13.64 & -18.29 & -17.70 & -12.02 \\
$\mathrm{Cs}^{+}$ & -21.32 & -20.63 & -14.20 & -17.03 & -16.48 & -10.85 \\
$\mathrm{M} 2$ & $\mathrm{RI}-\mathrm{MP} 2$ & & & $\mathrm{RI}-\mathrm{PBE}$ & & \\
$\mathrm{Li}^{+}$ & -40.46 & -39.67 & -32.71 & -43.37 & -42.48 & -35.44 \\
$\mathrm{Na}^{+}$ & -26.74 & -26.13 & -19.73 & -28.23 & -27.99 & -22.02 \\
$\mathrm{~K}^{+}$ & -21.64 & -21.03 & -14.72 & -19.94 & -19.63 & -14.05 \\
$\mathrm{Rb}^{+}$ & -20.90 & -20.23 & -13.66 & -17.98 & -17.36 & -11.82 \\
$\mathrm{Cs}^{+}$ & -21.49 & -20.82 & -14.21 & -16.72 & -16.13 & -10.67 \\
\hline
\end{tabular}

system, such as graphene). This conclusion was drawn purely on the basis of energetic considerations. The mobilities of these cations are expected to be even more enhanced when temperature effects are taken into account.

\section{Influence of the microhydration shell}

In order to investigate the influence of the microhydration shell on the adsorption of $\mathrm{M}^{+}$to pyrene and the competition between the $\mathrm{M}^{+}$-pyrene and $\mathrm{M}^{+}$-water interactions, potential energy curves as a function of the $\mathrm{M}^{+} \ldots$ pyrene perpendicular distance $\left(d\left(\mathrm{M}^{+} \ldots\right.\right.$ pyrene $\left.)\right)$ have been generated for the isolated $\mathrm{Li}^{+} / \mathrm{K}^{+}$ions and the corresponding microhydrated complexes $\mathrm{Li}^{+}\left(\mathrm{H}_{2} \mathrm{O}\right)_{4}$ and $\mathrm{K}^{+}\left(\mathrm{H}_{2} \mathrm{O}\right)_{8}$, respectively. During the optimization process, the pyrene molecule and the cation were fixed

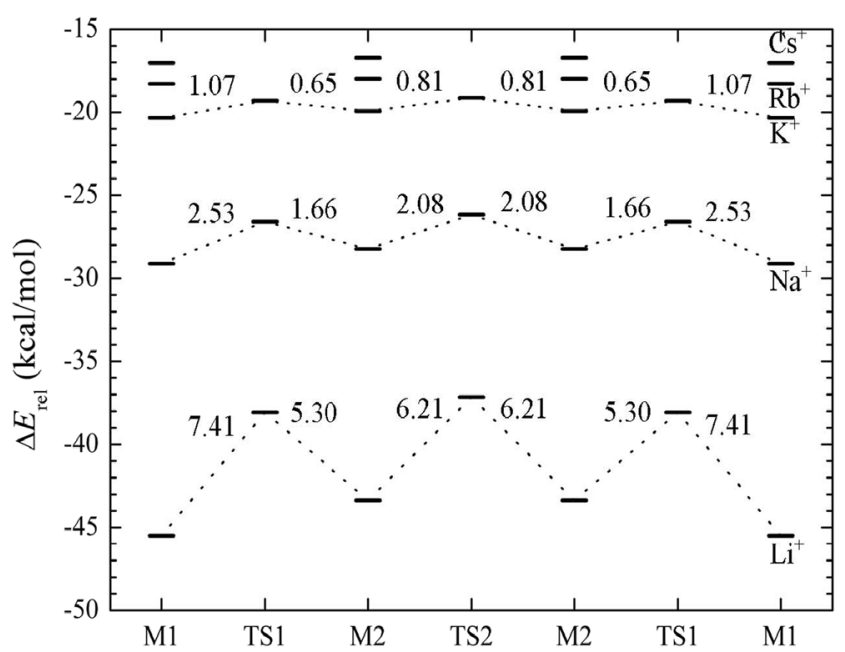

Fig. 4 Energy profiles and transition barriers (kcal/mol) for alkali metal cation-pyrene complexes and the water molecules were relaxed at each point on the potential energy curve. For both $\mathrm{Li}^{+}$and $\mathrm{K}^{+}$, representing small and big alkali metal cations, respectively, the position at the M2 site (Fig. 3) was considered. The interaction at the M1 site was expected to give very similar trends, and was therefore not taken into account.

The potential energy (PE) curves for the isolated and microhydrated $\mathrm{Li}^{+}$complexes with pyrene are presented in Fig. 5. The PE curve of the isolated $\mathrm{Li}^{+}$. pyrene complex has only one minimum (M2) at a distance of $\sim 1.8 \AA$ with an energy of $-45.5 \mathrm{kcal} / \mathrm{mol}$ (PBE/def2-TZVPP level, Table 2) with respect to the individual components at infinite separation. On the other hand, for the microhydrated $\mathrm{Li}^{+}\left(\mathrm{H}_{2} \mathrm{O}\right)_{4}$-pyrene complex, two minima - both significantly higher in energy than for the nonhydrated case - are found at distances of $d=2.3$ and $4.0 \AA$, respectively. Evidently, hydration strongly destabilizes the $\mathrm{Li}^{+}-$ pyrene complex. The local minimum of the PE curve for the microhydrated $\mathrm{Li}^{+}$observed at $2.3 \AA$ corresponds to the formation of an inner complex where $\mathrm{Li}^{+}$is in direct contact with the aromatic system, as in the case of the bare $\mathrm{Li}^{+}-$pyrene complex. However, the effect of hydration by four water molecules shifts the $\mathrm{Li}^{+} \sim 0.5 \AA$ further away from the pyrene plane. The other (global) minimum at $\sim 3.8 \AA$ corresponds to an outer complex where $\mathrm{Li}^{+}$is hydrated by four water molecules in a tetrahedral coordination (Fig. 5). Three water molecules from the coordination shell have hydrogen atoms oriented towards the pyrene plane; these $\mathrm{H}$ atoms form weak hydrogen bonds (lengths $\sim 2.5 \AA$ ) with the $\pi$-system. The outer complex is $\sim 5 \mathrm{kcal} / \mathrm{mol}$ more stable than the inner one. This indicates that $\mathrm{Li}^{+}$favors cation-water over cation- $\pi$ interactions.

For the isolated $\mathrm{K}^{+}$-pyrene complex (Fig. 6), a similar PE curve to that reported for the respective isolated $\mathrm{Li}^{+}$-pyrene complex (Fig. 5) is obtained. The minimum found at a distance of $\sim 2.8 \AA$ corresponds to the M2 site. The PE curve of the

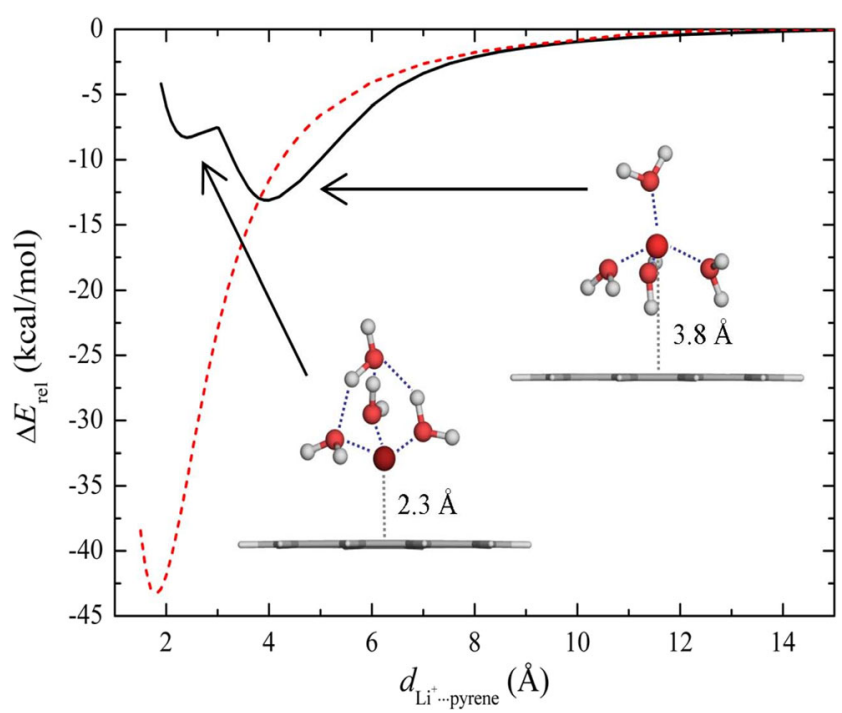

Fig. 5 Potential energy curves for isolated $\mathrm{Li}^{+}$-pyrene (dashed line) and microhydrated $\mathrm{Li}^{+}\left(\mathrm{H}_{2} \mathrm{O}\right)_{4}$-pyrene (solid line) complexes 


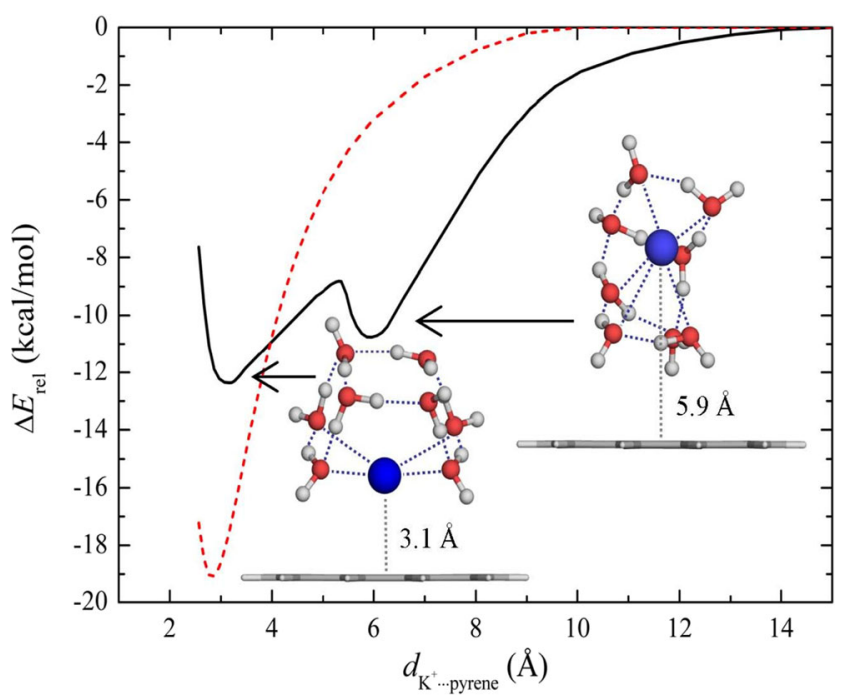

Fig. 6 Potential energy curves for isolated $\mathrm{K}^{+}$-pyrene (dashed line) and microhydrated $\mathrm{K}^{+}\left(\mathrm{H}_{2} \mathrm{O}\right)_{8}$-pyrene (solid line) complexes

microhydrated $\mathrm{K}^{+}\left(\mathrm{H}_{2} \mathrm{O}\right)_{8}$-pyrene complex has two minima, just like the $\mathrm{Li}^{+}\left(\mathrm{H}_{2} \mathrm{O}\right)_{4}$-pyrene complex. The minima reflect the formation of inner- and outer-sphere $\mathrm{K}^{+}\left(\mathrm{H}_{2} \mathrm{O}\right)_{8}$-pyrene complexes, respectively. However, the relative energetic stability of the inner compared to the outer microhydrated $\mathrm{K}^{+}\left(\mathrm{H}_{2} \mathrm{O}\right)_{8}-$ pyrene complex is very different from the relative energetic stability of the inner compared to the outer microhydrated $\mathrm{Li}^{+}$ complex. The cation in the inner microhydrated $\mathrm{K}^{+}\left(\mathrm{H}_{2} \mathrm{O}\right)_{8}-$ pyrene complex is located $\sim 3.1 \AA$ from the pyrene plane (about $0.3 \AA$ further than in the bare complex). This complex is more stable than the outer complex (with a $\mathrm{K}^{+} \ldots$ pyrene distance of $5.9 \AA$ ) by about $1.5 \mathrm{kcal} / \mathrm{mol}$. Thus, in contrast to $\mathrm{Li}^{+}, \mathrm{K}^{+}$favors cation $-\pi$ over cation-water interactions. Moreover, the complex is also stabilized by hydrogen bonds of $\mathrm{H}_{2} \mathrm{O} \cdots \pi$ type between two water molecules and the pyrene (Fig. 6), with $\mathrm{H} \cdots$ pyrene distances of about $2.5 \AA$. The microhydration shell of the inner complex is arranged in a hemisphere-like configuration around the $\mathrm{K}^{+}$cation, with only four of the eight water molecules coordinated directly to the cation (the $\mathrm{K}^{+} \cdots \mathrm{O}$ distances are about $2.8 \AA$ ). The remaining four water molecules form a square on top of the complex with $\mathrm{K}^{+} \ldots \mathrm{O}$ distances of 3.9-4.1 A. Overall, in the hemisphere-like water cluster, strong hydrogen bonds are formed among the water molecules with $\mathrm{H} \cdots \mathrm{O}$ distances of 21.4-1.7 $\AA$. The observed differences between the microhydrated pyrene $-\mathrm{Li}^{+}$and pyrene $-\mathrm{K}^{+}$clusters agree well with the conclusions drawn from a previous experimental investigation by Cabarcos et al. [29] of $\mathrm{Na}^{+} / \mathrm{K}^{+}-$(benzene) $)_{m}\left(\mathrm{H}_{2} \mathrm{O}\right)_{n}$ clusters, where similar differences between $\mathrm{Na}^{+}$and $\mathrm{K}^{+}$complexes were observed. In the $\mathrm{K}^{+}$clusters, the cation was stabilized by benzene molecules and water molecules were displaced further away, but in the $\mathrm{Na}^{+}$clusters, the water molecules remained (stabilized) in the first coordination shell. Similar findings were reported by Meng et al. [35] from their ab initio molecular dynamics study of microhydrated $\mathrm{Na}^{+}$and $\mathrm{K}^{+}$cations on a graphite surface. These different complexation patterns of hydrated alkali cations with aromatic systems can be attributed to ionic size selectivity effects [29], in which the interplay between several factors such as cation- $\pi$ interactions, cation-water complexation, and the hydrogen bonding of water to the $\pi$ system plays an important role.

To get a better understanding of the difference between the interactions of microhydrated $\mathrm{Li}^{+}$and $\mathrm{K}^{+}$cations with pyrene, we compared the electrostatic potential surfaces of both systems (Fig. 7). The electrostatic potential is a useful physical property, and calculated values of it (e.g., on a molecular surface) can indicate which parts of a molecular system are important for nonbonding interactions [54]. The calculated electrostatic potential was mapped onto the $0.001 \mathrm{e} / \mathrm{bohr}^{3}$ electron density isosurfaces for the structures at the global minima of the potential energy curves, i.e., the outer complex for the $\mathrm{Li}^{+}$case and the inner complex for $\mathrm{K}^{+}$(Figs. 5 and 6). A key factor in the configuration of the microhydrated cations on the pyrene surface is the cation radius. The small $\mathrm{Li}^{+}$cation polarizes water molecules more than $\mathrm{K}^{+}$does, and is screened by them from the pyrene $\pi$ system. The polarized water molecules in turn polarize a large part of the aromatic system of pyrene. On the other hand, the much larger $\mathrm{K}^{+}$cation-which is in direct contact with pyrene- directly polarizes the $\pi$-system more than the water molecules from its incomplete coordination shell. Moreover, the water molecules interact more weakly with pyrene than the water molecules in the $\mathrm{Li}^{+}\left(\mathrm{H}_{2} \mathrm{O}\right)_{4}$-pyrene system do.
Fig. 7a-b Calculated electrostatic potential (in hartrees) mapped onto the $0.001 \mathrm{e} / \mathrm{bohr}^{3}$ electron density isosurfaces for $\mathrm{Li}^{+}\left(\mathrm{H}_{2} \mathrm{O}\right)_{4}$-pyrene (a) and $\mathrm{K}^{+}\left(\mathrm{H}_{2} \mathrm{O}\right)_{8}$-pyrene $(\mathbf{b})$. The scale for the electrostatic potential is positive because the total charge on both systems is +1
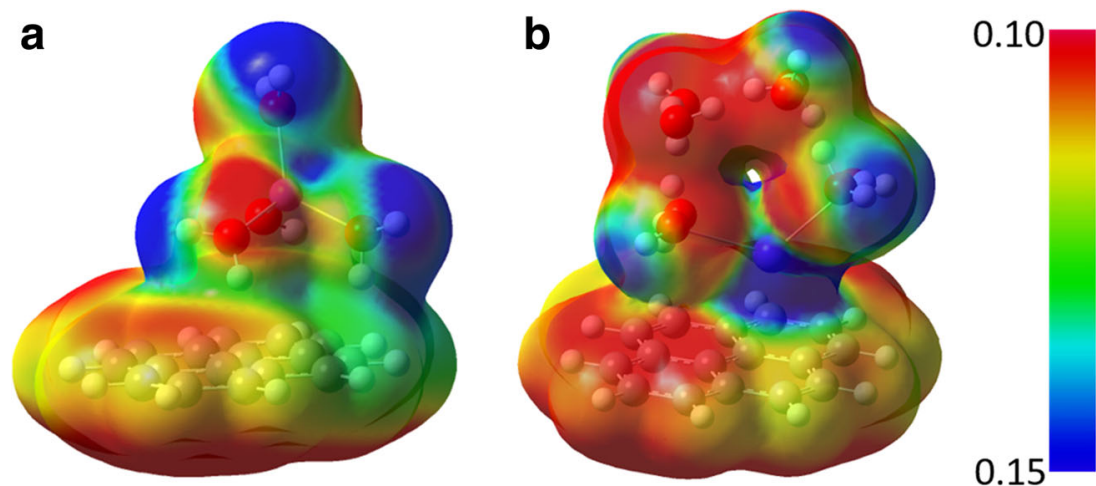


\section{Conclusions}

Cation $-\pi$ interactions have been investigated for $\mathrm{H}^{+}-$ pyrene and alkali metal cation $\mathrm{M}^{+}$-pyrene complexes ( $\mathrm{M}$ $=\mathrm{Li}, \mathrm{Na}, \mathrm{K}, \mathrm{Rb}$, and $\mathrm{Cs}$ ) by means of MP2 and DFT/PBE calculations. In $\mathrm{H}^{+}$-pyrene, the proton forms chemical bonds with different carbon atoms of pyrene. A detailed stability analysis of all possible protonation sites shows that the outer ring carbon atoms that are bonded to hydrogen atoms are preferred for protonation over the central carbon atoms. This is in accord with resonance effects based on valence bond theory. Analysis of the stabilities of the different protonation sites in pyrene showed that the peripheral carbon atoms (bonded to hydrogen atoms) are much more stable than the inner carbon atoms. The barriers between the stable structures protonated at the peripheral carbon atoms are relatively high (greater than $\sim 7 \mathrm{kcal} / \mathrm{mol}$ ). Only the transition barrier from the least stable site (II) to the most stable one (III, $\alpha$-carbon) is low $(2.3 \mathrm{kcal} / \mathrm{mol})$.

For the $\mathrm{M}^{+}$-pyrene complexes, two energy minima (M1 and M2) were found in which the cation is located above the outer and inner pyrene rings, respectively. For the smaller cations $\left(\mathrm{Li}^{+}\right.$and $\left.\mathrm{Na}^{+}\right), \mathrm{M} 1$ is more stable than M2 by about $2 \mathrm{kcal} / \mathrm{mol}$ for the $\mathrm{Li}^{+}$-pyrene complex. For the bigger cations $\left(\mathrm{K}^{+}, \mathrm{Rb}^{+}\right.$, and $\left.\mathrm{Cs}^{+}\right)$, the $\mathrm{M} 1$ and $\mathrm{M} 2$ structures present almost (within a few tenths of a $\mathrm{kcal} / \mathrm{mol}$ ) the same stability. Both the binding energies and the transition energy barriers between the outer (M1) and inner (M2) rings decrease with increasing cation size from $\mathrm{Li}^{+}$to $\mathrm{Cs}^{+}$. For $\mathrm{K}^{+}$, which represents an intermediate case between small and big alkali metal cations, the transition barrier heights are about $1 \mathrm{kcal} / \mathrm{mol}$. The transition barriers for the bigger $\mathrm{Rb}^{+}$and $\mathrm{Cs}^{+}$cations are estimated to be lower than $1 \mathrm{kcal} / \mathrm{mol}$, indicating practically barrierless transitions and high mobilities of these cations on the aromatic surface.

To investigate the influence of the water molecules that coordinate $\mathrm{M}^{+}$on its adsorption to pyrene, potential energy curves for the isolated $\mathrm{Li}^{+}$-pyrene and $\mathrm{K}^{+}$-pyrene and microhydrated $\mathrm{Li}^{+}\left(\mathrm{H}_{2} \mathrm{O}\right)_{4}$-pyrene and $\mathrm{K}^{+}\left(\mathrm{H}_{2} \mathrm{O}\right)_{8}$-pyrene complexes were calculated. $\mathrm{Li}^{+}$and $\mathrm{K}^{+}$were selected as representatives of small and big alkali metal cations, respectively. While only one minimum was found for the isolated complexes, the microhydrated complexes exhibited two minima, corresponding to an inner- and an outer-shell complex, respectively. For $\mathrm{Li}^{+}$, the outer complex was found to be more stable (by $\sim 5 \mathrm{kcal} / \mathrm{mol}$ ) than the inner one, indicating that $\mathrm{Li}^{+}$favors cation-water over cation $-\pi$ interactions. The relatively strong tetrahedral hydration shell of $\mathrm{Li}^{+}$remains intact upon adsorption to the aromatic system. Although two minima reflecting the inner and outer complexes were also found for the microhydrated $\mathrm{K}^{+}\left(\mathrm{H}_{2} \mathrm{O}\right)_{8}$-pyrene complex, the outer complex is more stable than the inner one by about $1.5 \mathrm{kcal} / \mathrm{mol}$, in contrast to the situation for $\mathrm{Li}^{+}$. Consequently, $\mathrm{K}^{+}$favors cation $-\pi$ over cation-water interactions. The loose hydration shell allows some water molecules to be displaced quite easily by the aromatic system, leading to partial dehydration of $\mathrm{K}^{+}$. The calculated electrostatic potential map showed that the cation radius is a key influence on the polarization of the water molecules and the aromatic system. The results demonstrated how ion size selectivity leads to the formation of different types of complexes (inner sphere and outer sphere, respectively) between microhydrated cations and aromatic systems. The formation mechanism of the complex depends on the balance between cation $-\pi$ interactions, cation-water complexation, and the hydrogen bonding of water to the $\pi$-system.

Acknowledgements Open access funding provided by University of Natural Resources and Life Sciences Vienna (BOKU). This work was supported by the Austrian Science Fund, project no. P20893-N19, and the Deutsche Forschungsgemeinschaft (SPP 1315), project no. GE1676/1-1. Computer time at the Vienna Scientific Cluster, project no. 70544 , is gratefully acknowledged.

Open Access This article is distributed under the terms of the Creative Commons Attribution 4.0 International License (http:// creativecommons.org/licenses/by/4.0/), which permits unrestricted use, distribution, and reproduction in any medium, provided you give appropriate credit to the original author(s) and the source, provide a link to the Creative Commons license, and indicate if changes were made.

\section{References}

1. Ma JC, Dougherty DA (1997) The cation $-\pi$ interactions. Chem Rev 97:1303-1324

2. Keiluweit M, Kleber M (2009) Molecular-level interactions in soils and sediments: the role of aromatic $\pi$-systems. Environ Sci Technol 43:3421-3429

3. Gokel GW, Barbour LJ, De Wall SL, Meadows ES (2001) Macrocyclic polyethers as probes to assess and understand alkali metal cation-pi interactions. Coord Chem Rev 222:127-154

4. Gallivan JP, Dougherty DA (1999) Cation $-\pi$ interactions in structural biology. Proc Natl Acad Sci USA 96:9459-9464

5. Singh NJ, Min SK, Kim DY, Kim KS (2009) Comprehensive energy analysis for various types of $\pi$-interaction. J Chem Theory Comput 5:515-529

6. Nicholas JB, Hay BP, Dixon DA (1999) Ab initio molecular orbital study of cation $-\pi$ binding between the alkali-metal cations and benzene. J Phys Chem A 103:1394-1400

7. Koyanagi GK, Bohme DK (2003) Kinetics and thermodynamics for the bonding of benzene to 20 main-group atomic cations: formation of half-sandwiches, full-sandwiches and beyond. Int J Mass Spect 227:563-575

8. Coletti C, Re N (2006) Theoretical study of alkali cation-benzene complexes: potential energy surfaces and binding energies with improved results for rubidium and cesium. J Phys Chem A 110: 6563-6570

9. Cheng J, Zhu W, Tang Y, Xu Y, Li Z, Chen K, Jiang H (2006) Effect of cation $-\pi$ interaction on NMR: a theoretical investigation on complexes of $\mathrm{Li}^{+}, \mathrm{Na}^{+}, \mathrm{Be}^{2+}$ and $\mathrm{Mg}^{2+}$ with aromatics. Chem Phys Lett 422:455-460 
10. Alberti M, Aguilar A, Pirani F (2009) Cation- $\pi$-anion interaction in alkali ion-benzene-halogen ion clusters. J Phys Chem A 113: 14741-14748

11. Alberti M, Aguilar A, Lucas JM, Pirani F (2010) A generalized formulation of ion $-\pi$ electron interactions: role of the nonelectrostatic component and probe of the potential parameter transferability. J Phys Chem A 114:11964-11970

12. Umadevi D, Sastry SG (2011) Molecular and ionic interaction with graphene nanoflakes: a computational investigation of $\mathrm{CO}_{2}, \mathrm{H}_{2} \mathrm{O}$, $\mathrm{Li}, \mathrm{Mg}, \mathrm{Li}^{+}$, and $\mathrm{Mg}^{2+}$ interaction with polycyclic aromatic hydrocarbons. J Phys Chem C 115:9656-9667

13. Lopez E, Lucas JM, de Andres J, Alberti M, Bofill JM, Bassi D, Aguilar A (2011) Cross-section energy dependence of the $\left[\mathrm{C}_{6} \mathrm{H}_{6-}\right.$ $\mathrm{M}]^{+}$adduct formation between benzene molecules and alkali ions $(\mathrm{M}=\mathrm{Li}, \mathrm{Na}, \mathrm{K})$. Phys Chem Chem Phys 13:15977-15984

14. Sharma B, Umadevi D, Sastry GN (2012) Contrasting preferences of $\mathrm{N}$ and $\mathrm{P}$ substituted heteroaromatics towards metal binding: probing the regioselectivity of $\mathrm{Li}^{+}$and $\mathrm{Mg}^{2+}$ binding to $(\mathrm{CH})_{6}$ ${ }_{-m}{ }_{n} \mathrm{~N}_{m} \mathrm{P}_{n}$. Phys Chem Chem Phys 14:13922-13932

15. Li R, Li Q, Liu Z, Li W, Luan F, Cheng J, Gong B (2012) Enhancing the function, non-additivity, and substitution position effect of the $\mathrm{Li}$ atom in the cation $-\pi$ interaction and its mechanism: an ab initio study of $\mathrm{Li}^{+} \cdots \mathrm{Li}$-substituted benzene complexes. Mol Phys 110:65-74

16. Lamoureux G, Orabi EA (2012) Molecular modelling of cation- $\pi$ interactions. Mol Simul 38:704-722

17. Orabi EA, Lamoureux $G$ (2012) Cation $-\pi$ and $\pi-\pi$ interactions in aqueous solution studied using polarizable potential models. J Chem Theor Comput 8:182-193

18. Dinadayalane TC, Hassan A, Leszczynski J (2012) A theoretical study of cation $-\pi$ interactions: $\mathrm{Li}^{+}, \mathrm{Na}^{+}, \mathrm{K}^{+}, \mathrm{Be}^{2+}, \mathrm{Mg}^{2+}$ and $\mathrm{Ca}^{2+}$ complexation with mono- and bicyclic ring-fused benzene derivatives. Theor Chem Accounts 131:1131

19. Peles-Lemli B, Kannar D, Nie JC, Li H, Kunsagi-Mate S (2013) Some unexpected behavior of the adsorption of alkali metal ions onto the graphene surface under the effect of external electric field. $\mathrm{J}$ Phys Chem C 117:21509-21515

20. Alberti M, Lago NF (2013) Competitive solvation of $\mathrm{K}^{+}$by $\mathrm{C}_{6} \mathrm{H}_{6}$ and $\mathrm{H}_{2} \mathrm{O}$ in the $\mathrm{K}^{+}-\left(\mathrm{C}_{6} \mathrm{H}_{6}\right)_{n}-\left(\mathrm{H}_{2} \mathrm{O}\right)_{\mathrm{m}}(\mathrm{n}=1-4 ; \mathrm{m}=1-6)$ aggregates. Eur Phys J D 67:73

21. Mahadevi AS, Sastry GN (2013) Cation $-\pi$ interaction: its role and relevance in chemistry, biology, and material science. Chem Rev 113:2100-2138

22. Hassan A, Dinadayalane TC, Grabowski SJ, Leszczynski J (2013) Structural, energetic, spectroscopic and QTAIM analyses of cation $-\pi$ interactions involving mono- and bi-cyclic ring fused benzene systems. Phys Chem Chem Phys 15:20839-20856

23. Khanmohammadi A, Raissi H, Mollania F, Hokmabadi L (2014) Molecular structure and bonding character of mono and divalent metal cations $\left(\mathrm{Li}^{+}, \mathrm{Na}^{+}, \mathrm{K}^{+}, \mathrm{Be}^{2+}, \mathrm{Mg}^{2+}\right.$, and $\left.\mathrm{Ca}^{2+}\right)$ with substituted benzene derivatives: AIM, NBO, and NMR analyses. Struct Chem 25:1327-1342

24. Zaboli M, Raissi H (2015) Structural, QTAIM, thermodynamic properties, bonding, aromaticity and NMR analyses of cation-pi interactions of mono and divalent metal cations $\left(\mathrm{Li}^{+}, \mathrm{Na}^{+}, \mathrm{K}^{+}\right.$, $\mathrm{Be}^{2+}, \mathrm{Mg}^{2+}$, and $\mathrm{Ca}^{2+}$ ) with substituted pyrazine derivatives. $\mathrm{J}$ Theor Comput Chem 14:1550044

25. Li ZH, Liu J, Qiao M, Fan K-N (2009) A theoretical study on the metal cation- $\pi$ complexes of $\mathrm{Zn}^{2+}$ and $\mathrm{Cd}^{2+}$ with benzene and cyclohexene. Mol Phys 107:1271-1282

26. Amicangelo JC, Armentrout PB (2000) Absolute binding energies of alkali-metal cation complexes with benzene determined by threshold collision-induced dissociation experiments and ab initio theory. J Phys Chem A 104:11420-11432

27. Sunner J, Nishizawa K, Kebarle P (1981) Ion-solvent molecule interactions in the gas-phase - the potassium-ion and benzene. $\mathrm{J}$ Phys Chem 85:1814-1820
28. Cabarcos OM, Weinheimer CJ, Lisy JM (1998) Competitive solvation of $\mathrm{K}^{+}$by benzene and water: cation $-\pi$ interactions and $\pi$ hydrogen bonds. J Chem Phys 108:5151-5154

29. Cabarcos OM, Weinheimer CJ, Lisy JM (1999) Size selectivity by cation $-\pi$ interactions: solvation of $\mathrm{K}^{+}$and $\mathrm{Na}^{+}$by benzene and water. J Chem Phys 110:8429-8435

30. Burk P, Tammiku-Taul J, Tamp S, Sikk L, Sillar K, Mayeux C, Gal J-F, Maria P-C (2009) Computational study of cesium cation interactions with neutral and anionic compounds related to soil organic matter. J Phys Chem A 113:10734-10744

31. Gal J-F, Maria P-C, Decouzon M, Mó O, Yanez M, Abboud JLM (2003) Lithium-cation/ $\pi$ complexes of aromatic systems. The effect of increasing the number of fused rings. J Am Chem Soc 125: 10394-10401

32. Zhao Y, Truhlar DG (2008) The M06 suite of density functionals for main group thermochemistry, thermochemical kinetics, noncovalent interactions, excited states, and transition elements: two new functionals and systematic testing of four M06-class functionals and 12 other functionals. Theor Chem Account 120:215-241

33. Shekar SC, Swathi RS (2015) Cation $-\pi$ interactions and rattling motion through two-dimensional carbon networks: graphene vs graphynes. J Phys Chem C 119:8912-8923

34. Sun ML, Tang WC, Ren QQ, Wang SK, Yu J, Du YH, Zhang YC (2015) First-principles study of the alkali earth metal atoms adsorption on graphene. Appl Surf Sci 356:668-673

35. Meng S, Chakarov DV, Kasemo B, Gao S (2004) Two-dimensional hydration shells of alkali metal ions at a hydrophobic surface. J Chem Phys 121:12572-12576

36. Schmidt MWI, Noack AG (2000) Black carbon in soils and sediments: analysis, distribution, implications, and current challenges. Glob Biogeochem Cycles 14:777-793

37. Nieman R, Das A, Aquino AJA, Amorim RG, Machado FBC, Lischka $H$ (2017) Single and double carbon vacancies in pyrene as first models for graphene defects: a survey of the chemical reactivity toward hydrogen. Chem Phys 482:346-354. doi:10.1016/j.chemphys.2016.08.007

38. Feyereisen M, Fitzgerald G, Komornicki A (1993) Use of approximate integrals in $a b$ initio theory - an application in MP2 energy calculations. Chem Phys Lett 208:359-363

39. Vahtras O, Almlöf J, Feyereisen M (1993) Integral approximations for LCAO-SCF calculations. Chem Phys Lett 213:514-518

40. Perdew JP, Yue W (1986) Accurate and simple density functional for the electronic exchange energy - generalized gradient approximation. Phys Rev B 33:8800-8802

41. Perdew JP, Burke K, Ernzerhof M (1996) Generalized gradient approximation made simple. Phys Rev Lett 77:3865-3868

42. Weigend F, Häser M, Patzelt H, Ahlrichs R (1998) RI-MP2: optimized auxiliary basis sets and demonstration of efficiency. Chem Phys Lett 294:143-152

43. Weigend F, Köhn A, Hättig C (2002) Efficient use of the correlation consistent basis sets in resolution of the identity MP2 calculations. J Chem Phys 116:3175-3183

44. Schäfer A, Huber C, Ahlrichs R (1994) Fully optimized contracted Gaussian-basis sets of triple zeta valence quality for atoms $\mathrm{Li}$ to $\mathrm{Kr}$. J Chem Phys 100:5829-5835

45. Quinonero D, Garau C, Frontera A, Ballester P, Costa A, Deyà PM (2005) Structure and binding energy of anion $-\pi$ and cation $-\pi$ complexes: a comparison of MP2, RI-MP2, DFT, and DF-DFT methods. J Phys Chem A 109:4632-4637

46. Leininger T, Nicklass A, Küchle W, Stoll H, Dolg M, Bergner A (1996) The accuracy of the pseudopotential approximation: nonfrozen-core effects for spectroscopic constants of alkali fluorides $\mathrm{XF}$ (X = K, Rb, Ca). Chem Phys Lett 255:274-280

47. Weigend F, Ahlrichs R (2005) Balanced basis sets of split valence, triple zeta valence and quadruple zeta valence quality for $\mathrm{H}$ to $\mathrm{Rn}$ : design and assessment of accuracy. Phys Chem Chem Phys 7: 3297-3305 
48. Boys SF, Bernardi F (1970) Calculation of small molecular interactions by differences of separate total energies - some procedures with reduced errors. Mol Phys 19:553

49. Ahlrichs R, Bär M, Häser M, Horn H, Kölmel C (1989) Electronicstructure calculations on workstation computers - the program system Turbomole. Chem Phys Lett 162:165-169

50. Mohajeri A, Karimi E (2006) AIM and NBO analyses of cation $-\pi$ interaction. J Mol Struct 774:71-76

51. Maksić ZB, Kovačević B, Kovaček D (1997) Simple ab initio model for calculating the absolute proton affinity of aromities. J Phys Chem A 101:7446-7453
52. Okazaki T, Laali KK (2004) Electrophilic and oxidative chemistry of pyrene and its non-alternant isomers: theoretical (DFT, GIAONMR, NICS) study of protonation carbocations and oxidation dications from pyrene, azupyrene (dicyclopenta[ef, $k l]$ heptalene) and dicyclohepta[ed,gh]pentalene. Org Biomol Chem 2:2214-2219

53. Laali KK (1996) Stable ion studies of protonation and oxidation of polycyclic arenes. Chem Rev 96:1873-1906

54. Politzer P, Murray JS, Clark T (2015) Mathematical modeling and physical reality in noncovalent interactions. J Mol Model 21:15 